\title{
RNA interference-mediated silencing of Stat5 induces apoptosis and growth suppression of hepatocellular carcinoma cells
}

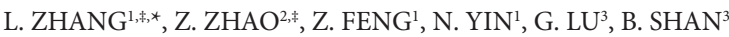 \\ ${ }^{1}$ Department of Clinical Laboratory, The Third Hospital of Hebei Medical University, Shijiazhuang 050051, Hebei Province, China; ${ }^{2}$ Department \\ of Clinical Laboratory, Yiling Hospital, Shijiazhuang 050091, Hebei Province, China; ${ }^{3}$ Research Center, The Forth Hospital of Hebei Medical \\ University, Shijiazhuang 050081, Hebei Province, China
}

*Correspondence: zhanglijie1971@126.com

${ }^{*}$ Contributed equally to this work.

Received October 4, 2011 / Accepted December 7, 2011

\begin{abstract}
It has been reported that Stat5 is overexpressed in a variety of human cancer cell lines and primary tumors. Inhibition of Stat5 in tumor cell lines has been associated with growth suppression and induction of apoptosis. However, no one of published studies have investigated the expression and role of Stat5 in hepatocellular carcinoma. In this study, we used human hepatocellular carcinoma cell line SMMC7721 as a model to demonstrate that Stat5 was highly expressed in these cells. Next we showed that RNAi mediated Stat5 knockdown could inhibit the proliferation and induce the apoptosis of SMMC7721 cells in vitro. Furthermore, we demonstrated that Stat5 knockdown inhibited the growth and induced the apoptosis of SMMC7721 cells in xenografts in nude mice. Taken together, our in vitro and in vivo data suggest that Stat 5 plays an important role in human hepatocellular carcinoma. Inhibition of Stat 5 by RNAi holds promise to be a novel gene therapy vector for hepatocellular carcinoma.
\end{abstract}

Key words: hepatocellular carcinoma, SMMC7721, RNA interference, Stat5, apoptosis

The signal transducers and activators of transcription (Stat) factors are the key effectors of signaling downstream of cytokine and growth factor receptors. Stat is one of the family of cytoplasmic transcription factors that transmit the signals, usually generated at cell surface, to the nucleus where Stat binds to specific DNA promoter sequences and consequently regulate gene expression. Seven different Stat (Stat1, Stat2, Stat3, Stat4, Stat5a, Stat5b, and Stat6) encoded by distinct genes have been identified in mammalian cells [1]. Accumulating evidence suggests that Stat5, a typical member of Stat family, functions as a survival protein in a number of normal and malignant cells of hematopoietic origin [2]. Constitutive activation of Stat5 is known to be present in a variety of blood-derived malignancies including chronic myelogenous leukemia (CML). Inhibition of Stat 5 activation in tumor cell lines has been associated with growth suppression and induction of apoptosis $[3,4]$. These findings suggest that Stat 5 could be a novel molecular target for therapeutic intervention in human cancer [5].

However, the expression and role of Stat 5 in hepatocellular carcinoma cells remain largely unknown. We hypothesized that Stat5 may play a role in the regulation of proliferation and apoptosis in cancer cells of hepatocellular carcinoma. Therefore, we employed hepatocellular carcinoma cell line SMMC7721 as a model, which was established from a Chinese male patient with hepatocellular carcinoma. This study was designed to examine the expression of Stat 5 protein in SMMC7721 cells and further investigate the role of Stat 5 in the tumorigenesis of hepatocellular carcinoma by in vitro cell study and in vivo xenograft study in nude mice.

\section{Materials and methods}

Cell culture. Cell lines SMMC7721, K562, mouse ascites hepatomas cell line H22 and murine mammary carcinomas cell line HA8911 were obtained from the Research Center of the Fourth Hospital of Hebei Medical University, and cultured in RPMI-1640 medium supplemented with $2 \mathrm{mmol} / \mathrm{L}$ Glutamax, $100 \mathrm{U} / \mathrm{ml}$ penicillin, $100 \mu \mathrm{g} / \mathrm{ml}$ streptomycin, $10 \mathrm{mmol} / \mathrm{l}$ HEPES (Invitrogen, Carlsbad, USA) and 10\% FCS (Sijiqing, Hangzhou, China). Cell lines were maintained in a 5\% CO2 
incubator at $37^{\circ} \mathrm{C}$ and passaged using trypsin/EDTA (Invitrogen, Carlsbad, USA).

Construction of RNA interference vector targeting Stat5. Stat 5 is encoded by two highly homologous genes Stat $5 \mathrm{a}$ and Stat5b [6]. Therefore, three small interference RNA (siRNA) sequences targeting the shared part of both the Stat5a and Stat5b genes (NM_003152.2 and NM_012448.3) were designed to inhibit these two genes simultaneously. The three siRNA oligonucleotide sequences were as follows: 1. ATGCCATTGACTTGGACAA; 2. GATCAAGCTGGGGCACTAC; and 3. CCTGGATGAGACCATGGAT. The Stat5 short hairpin RNA (Stat5 shRNA) template sequence structure was as follows: BamHI+ Sense + Loop+ Antisense + terminal signal + SalI+HindIII. The designed oligos were synthesized by GeneSil Biotechnology (Wuhan, China). The three specific recombinant plasmid vectors were constructed and named Pgenesil-1-Stat5A1, Pgenesil-1-Stat5A2, and Pgenesil-1Stat5A3, respectively. Plasmid expressing irrelevant shRNA with a random combination was used as negative control and named Pgenesil-1-HK. All the recombinant vectors were confirmed by DNA sequencing analysis.

Transfection. SMMC7721 cells in the exponential phase of growth were plated in 6 -well plates at $2 \times 10^{5}$ cells/well, grown for $24 \mathrm{~h}$, then transfected with Pgenesil-1-Stat5A1, Pgenesil-1-Stat5A2, Pgenesil-1-Stat5A3, or Pgenesil-1-HK by lipofectamine ${ }^{\mathrm{TM}} 2000$ (Invitrogen, Carlsbad, USA) according to the manufacturer's protocol. Transfection efficiency was monitored by the detection of enhanced green fluorescent protein (EGFP) under laser scanning confocal microscope at $48 \mathrm{~h}$ after transfection. The vector with the highest efficiency in inhibiting Stat5 expression was selected based on semiquantitative RT-PCR and Western blot analysis and used for the follow-up experiments.

Semi-quantitative PCR. Total RNA was extracted from cells and tissues using Trizol (Gibco, Gaithersburg, USA). Reverse transcription (RT) was performed by RT kit (Takara, Dalian, China) according to the manufacturer's instructions. The forward and reverse primer sequences for Stat 5 were as follows: 5'GAGTCTCAGTTCAGTGTTGGCAGC3'; and 5'AGT CACTAAAGCGCAACAAGAAGGTC3'. The forward and reverse primer sequences for $\beta$-actin were as follows: 5'TGAGACCTTC AACACCCCAG3'; and 5'GCCATCTC TTGCTCGAAGTC3'. Level of Stat5 mRNA expression in the tested samples was normalized to the corresponding $\beta$-actin mRNA transcript.

Western blot. Lysate was taken from cells and the protein concentration of the lysate was determined by BCA method, $100 \mu \mathrm{g}$ protein was loaded in each lane and subjected to $8 \%$ SDS-PAGE gel electrophoresis, then transferred to nitrocellulose membrane for immunoblotting. The membranes were probed with antibodies against Stat 5 or $\beta$-actin (Cell Signal, Danvers, USA) overnight at $4^{\circ} \mathrm{C}$. Then the membranes were washed with TBST, and incubated for $2 \mathrm{~h}$ with HRPconjugated rabbit anti-mouse secondary antibody (Santa Cruz, USA ). Immunoreactive bands were visualized with
3, 3-diaminobenzidine (DAB) (Zhongshan Biotechnology, Beijing, China).

Cell viability assay. Cell proliferation was assessed by MTT (3-(4, 5-dimethylthiazole-2-yl)-2,5-diphenyltetrazolium bromide) assay as described previously [7]. Briefly, SMMC7721 cells were seeded into a 96-well plate at $2 \times 10^{4}$ cells/well. After incubation for $12 \mathrm{~h}$, the cells were treated with serum-free medium, Pgenesil-1-HK, or Pgenesil-1-Stat5A1, respectively for $8 \mathrm{~h}$. Then the medium was replaced with fresh complete medium and the culture was further incubated for $48 \mathrm{~h}$. Next, the media was carefully removed, and $150 \mu \mathrm{l}$ serum-free RPMI- 1640 medium containing $15 \mu \mathrm{l}$ mg/ml MTT (Promega, Madison, USA) was added to each well. Cells were incubated at $37^{\circ} \mathrm{C}$ for $4 \mathrm{~h}$, then the medium was totally removed and $150 \mu$ l DMSO (Promega, Madison, USA) was added to each well. The optical absorbance (A) of each well was measured at 570 and $630 \mathrm{~nm}$ with a microplate reader. The percentage of cell viability was calculated as follows: (A of experimental group/A of control group) $\times 100 \%$.

Flow cytometry analysis for apoptosis. DNA content was determined by flow cytometry using PI staining (Promega, Madison, USA). Briefly, cells were harvested, washed twice with PBS and fixed in $80 \%$ ethanol at $4^{\circ} \mathrm{C}$ for at least $12 \mathrm{~h}$. After being centrifuged, the cells were incubated in PBS containing $200 \mu \mathrm{g} / \mathrm{ml}$ DNase-free RNaseA at $37^{\circ} \mathrm{C}$ for $20 \mathrm{~min}$. Then the cells were incubated in PBS containing $50 \mu \mathrm{g} / \mathrm{ml}$ PI for $30 \mathrm{~min}$ on ice in the dark. For each sample, $3 \times 10^{4}$ cells were analyzed for DNA content using a Coulter EPICS XLTM from Beckman Coulter and CellFit software.

Transmission electron microscopy. Cells were collected, centrifuged at $200 \mathrm{~g}$ for $10 \mathrm{~min}$ and washed twice with PBS. The cells were then fixed with $2.5 \%$ glutaraldehyde in PBS at $4^{\circ} \mathrm{C}$ for $2 \mathrm{~h}$ and washed three times in PBS. After being fixed in $1 \%$ osmium tetroxide, cells were dehydrated using an ethanol series, embedded in epoxy resin, and cut into ultrathin slices. After being stained with uranium acetate and lead citrate, the slices were observed under a transmission electron microscope (JEM-2100H II, Japan) and electron micrographs were taken.

Xenograft in nude mice. Balb/c-nu/nu mice were obtained from Chinese Academy of Medical Sciences (Beijing) and maintained according to "NIH Guide for the Care and Use of Laboratory Animals". The study was approved by the Ethics Board of Hebei Medical University. SMMC7721 cells were resuspended in serum-free medium at $2 \times 10^{7}$ cells $/ \mathrm{ml}$, and $200 \mu \mathrm{l}$ cell suspension was injected into the right flank of each nude mice. The mice were randomly divided into test group and control group when the SMMC7721 tumor cells xenograft was incubated for $15 \mathrm{~d}$. Mice in each group were intratumorally injected with $200 \mu$ l Pgenesil-1-Stat5A1, Pgenesil-1-HK, NS (Blank group), respectively every 2 days, for a total of 10 injections. The process of tumorigenesis was monitored and the tumor volumes were calculated as $\left(a \times b^{2}\right) / 2[8]$ ( $a$ and $\mathrm{b}$ represented the long and short axis of the tumor, respectively) every 5 days. On the thirty-fifth day, tumors were harvested. 
A

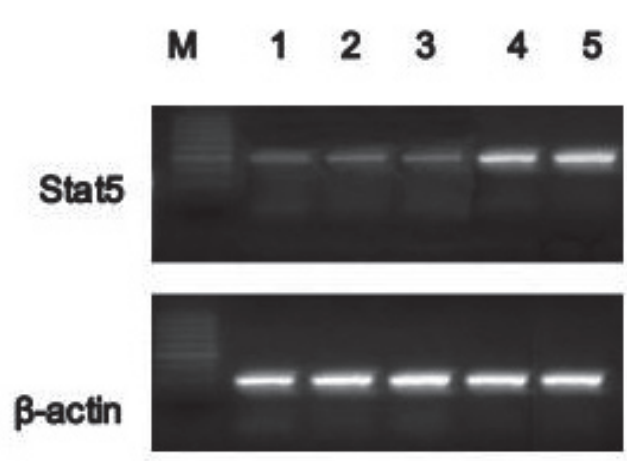

C

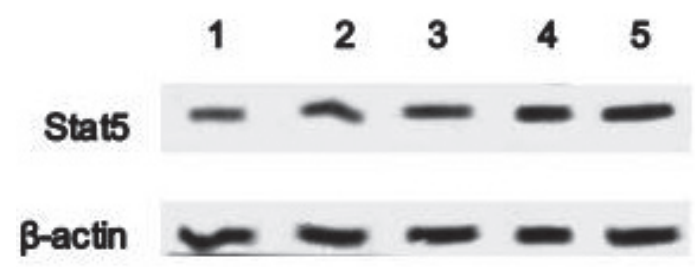

B
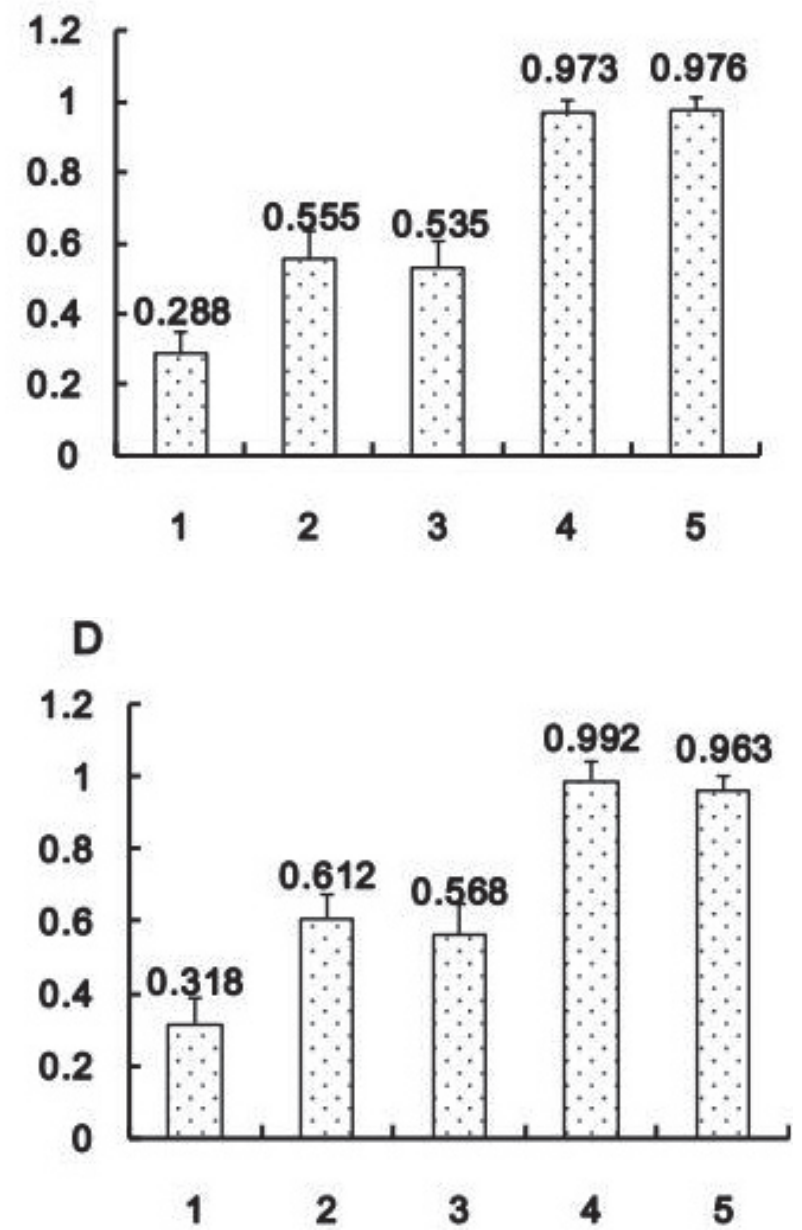

Fig. 1. shRNA mediated silencing of Stat5 expression in SMMC7721 cells. A. Representative RT-PCR results showing the relative Stat5 mRNA level in different groups. M: Marker; Lane 1: Pgenesil-1-Stat5A1; Lane 2: Pgenesil-1-Stat5A2; Lane 3: Pgenesil-1-Stat5A3; Lane 4: Pgenesil-1-HK; Lane 5: cells without transfection. B. Quantification of Stat $5 \mathrm{mRNA}$ level (normalized to the $\beta$-actin mRNA level) as shown in A ( $\mathrm{n}=3$ ). All data were expressed as means \pm S.D and the bar represented the mean of data obtained from three experiments. ${ }^{*} p<0.05$ compared to the cells without transfection. C. Representative Western blots showing the relative Stat5 protein level in different groups. Lane 1: Pgenesil-1-Stat5A1; Lane 2: Pgenesil-1-Stat5A2; Lane 3: Pgenesil-1-Stat5A3; Lane 4: Pgenesil-1-HK; Lane 5: cells without transfection. D. Quantification of Stat5 protein level (normalized to the $\beta$-actin protein level) as shown in C $(n=3)$. All data were expressed as means \pm S.D and the bar represented the mean of data obtained from three experiments. ${ }^{*} p<0.05$ compared to the cells without transfection.

The tumor inhibition rate was defined as reduced volume of tumor: (tumor volume before injection - tumor volume at the end)/tumor volume before injection.

Statistical analysis. Average values were expressed as mean $\pm \mathrm{SD}$. The statistical significance of differences in mean values was assessed by Student's test and A one-way analysis of variance (ANOVO) using SPSS 10.0 statistical software. $p<0.05$ was considered statistically significant.

\section{Results}

Evaluation of Stat 5 knockdown in SMMC7721 cells. To investigate the role of Stat 5 in hepatocellular carcinoma cells, we made Stat5 shRNA constructs to knockdown Stat5 in these cells. After transfection of different Stat5 shRNA constructs into these cells, we detected Stat5 expression by RT-PCR and Western blot analysis. RT-PCR results showed that the integral optical density (IOD) ratio of Stat5 mRNA relative to $\beta$-actin in experimental groups (cells without transfection; Pgenesil-1-HK; Pgenesil-1-Stat5A1; Pgenesil-1-Stat5A2; Pgenesil-1-Stat5A3) was $0.976 \pm 0.038$, $0.973 \pm 0.033,0.288 \pm 0.063,0.555 \pm 0.082$, and $0.535 \pm 0.073$, respectively. The inhibition rate of Stat 5 mRNA expression among Pgenesil-1-Stat5 shRNA expression vectors (Pgenesil-1-Stat5A1; Pgenesil-1-Stat5A2; Pgenesil-1-Stat5A3) was $70.43 \%, 43.02 \%$, and $45.07 \%$, respectively (Fig. 1A, B). 
A
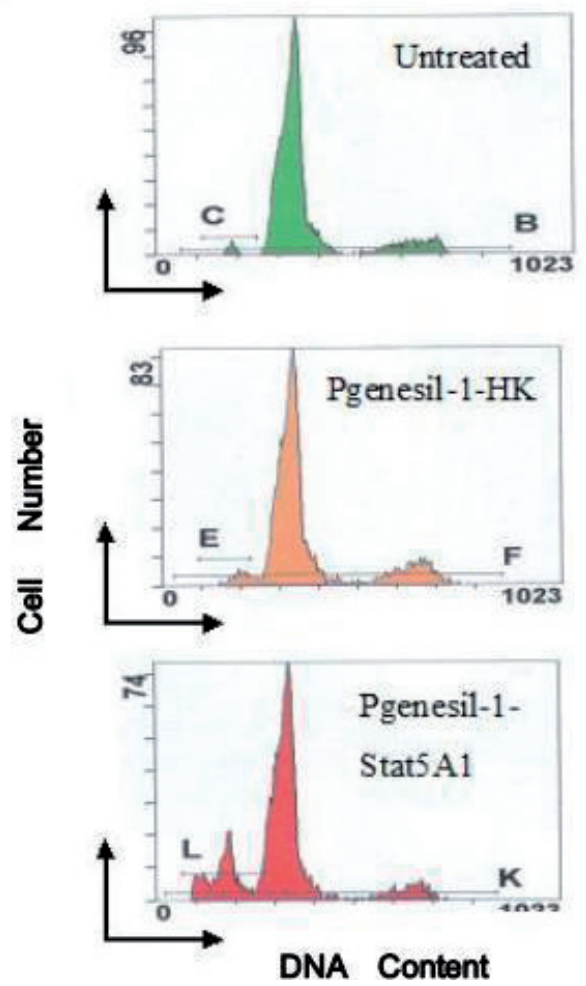

B
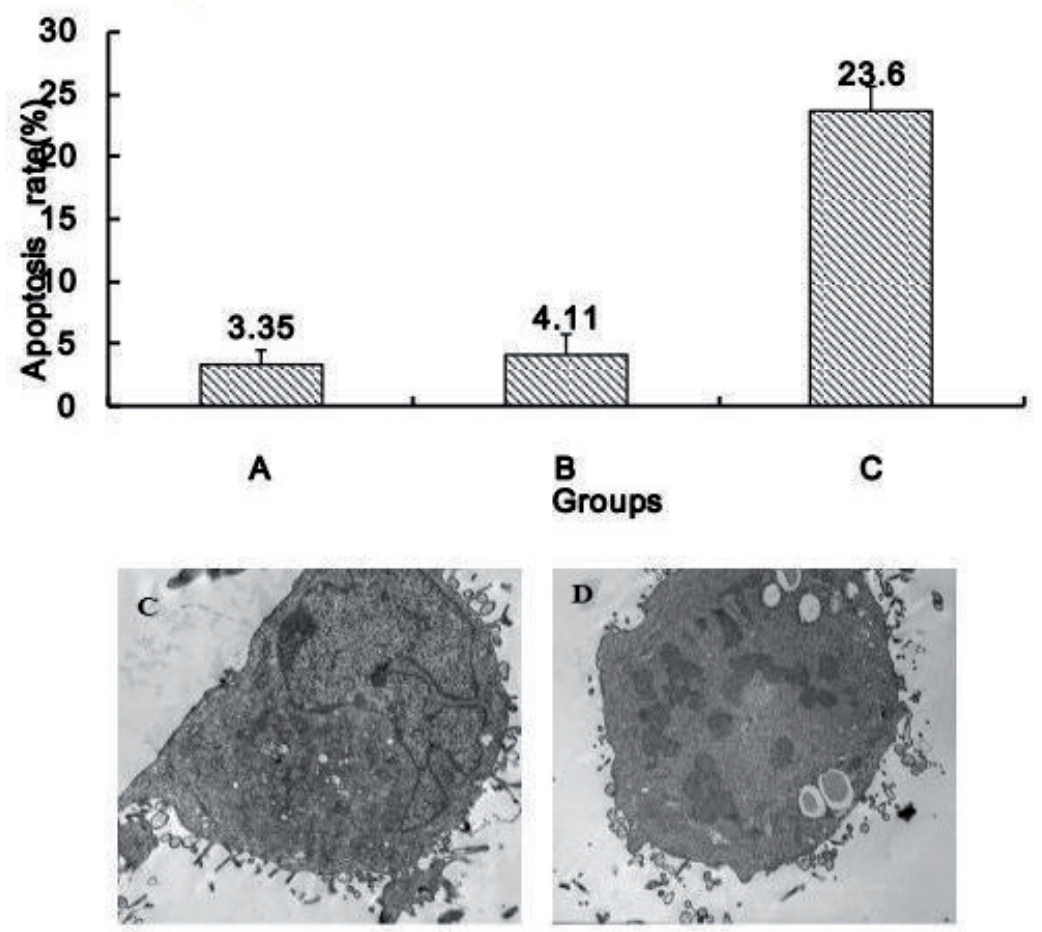

Fig. 2. Stat5 knockdown induces the apoptosis of SMMC7721 cells. A. Representative flow cytometry histograms of different groups. Typical subdiploid population or sub-G1 peak was observed in SMMC7721 cells treated with Pgenesil-1-Stat5A1. B. Quantification of apoptosis rate in different groups based on histograms shown in $A(n=3)$. All data were expressed as means \pm S.D and the bar represented the mean of data obtained from three experiments. ${ }^{*} p<0.05$ compared to the cells without transfection. C. Transmission electron microscopy showing the ultrastructure of SMMC7721 cells transfected with Pgenesil-1-HK. D. Transmission electron microscopy showing the ultrastructure of apoptotic SMMC7721 cells transfected with Pgenesil-1-Stat5A1. The cells exhibited typical apoptotic features such as chromatin condensation, nuclear fragmentation, presence of apoptotic bodies, and cytoplasm vacuolization. Magnification: $\mathbf{x} 5000$.

Moreover, Western blot results showed that the IOD ratio of Stat 5 protein relative to $\beta$-actin in experimental groups (cells without transfection; Pgenesil-1-HK; Pgenesil-1-Stat5A1; Pgenesil-1-Stat5A2; Pgenesil-1-Stat5A3) was $0.963 \pm 0.042$, $0.992 \pm 0.053,0.318 \pm 0.072,0.612 \pm 0.065$, and $0.568 \pm 0.083$, respectively. The inhibition rate of Stat5 protein expression among Pgenesil-1-Stat5 shRNA expression vectors (Pgenesil-1-Stat5A1; Pgenesil-1-Stat5A2; Pgenesil-1-Stat5A3) was $67.45 \%, 37.36 \%$, and $41.86 \%$, respectively (Fig. 1C, D). These results demonstrated that Stat 5 expression at both mRNA and protein levels was significantly decreased in SMMC7721 cells transfected with Stat5 shRNA compared to control group ( $p$ $<0.05)$. Pgenesil-1-Stat5A1 construct was especially effective in silencing Stat5 in SMMC7721 cells and selected for the following experiments.

Stat5 knockdown promotes the apoptosis of SMMC7721 cells. SMMC7721 cells were treated with serum-free medium (blank group), Pgenesil-1-HK, or Pgenesil-1-Stat5A1. Cell viability assay showed that the viability of the three groups was $0.711 \pm 0.036,0.715 \pm 0.045$, and $0.400 \pm 0.026$, respectively. Stat5 shRNA significantly inhibited the proliferation of SMMC7721 cells $(p<0.05)$ and the inhibitory rate was $51 \%$. We speculated that the inhibition of cell growth by Stat 5 shRNA is due to the induction of apoptosis. Therefore, we performed flow cytometry analysis and found the typical sub-diploid population or sub-G1 peak in SMMC7721 cells treated with Pgenesil-1-Stat5A1 (Fig. 2A). The amount of apoptotic cells in the group treated with Pgenesil-1-Stat5A1 increased significantly $(23.60 \pm 1.99 \%)$ compared to the untreated group $(3.35 \pm 1.20 \%)(p<0.05$, Fig. $2 B)$. Furthermore, we employed transmission electron microscopy to analyze the ultrastructural changes in SMMC7721 cells transfected with Pgenesil-1-Stat5A1. We observed typical apoptotic features characterized by volume reduction, chromatin condensation, nuclear fragmentation, presence of apoptotic bodies, and cytoplasm vacuolization (Fig. 2C). Similar induction of apoptosis of SMMC7721 cells was observed using other two shRNA constructs Pgenesil-1-Stat5A2 and Pgenesil-1-Stat5A3 although the effects were not as strong 

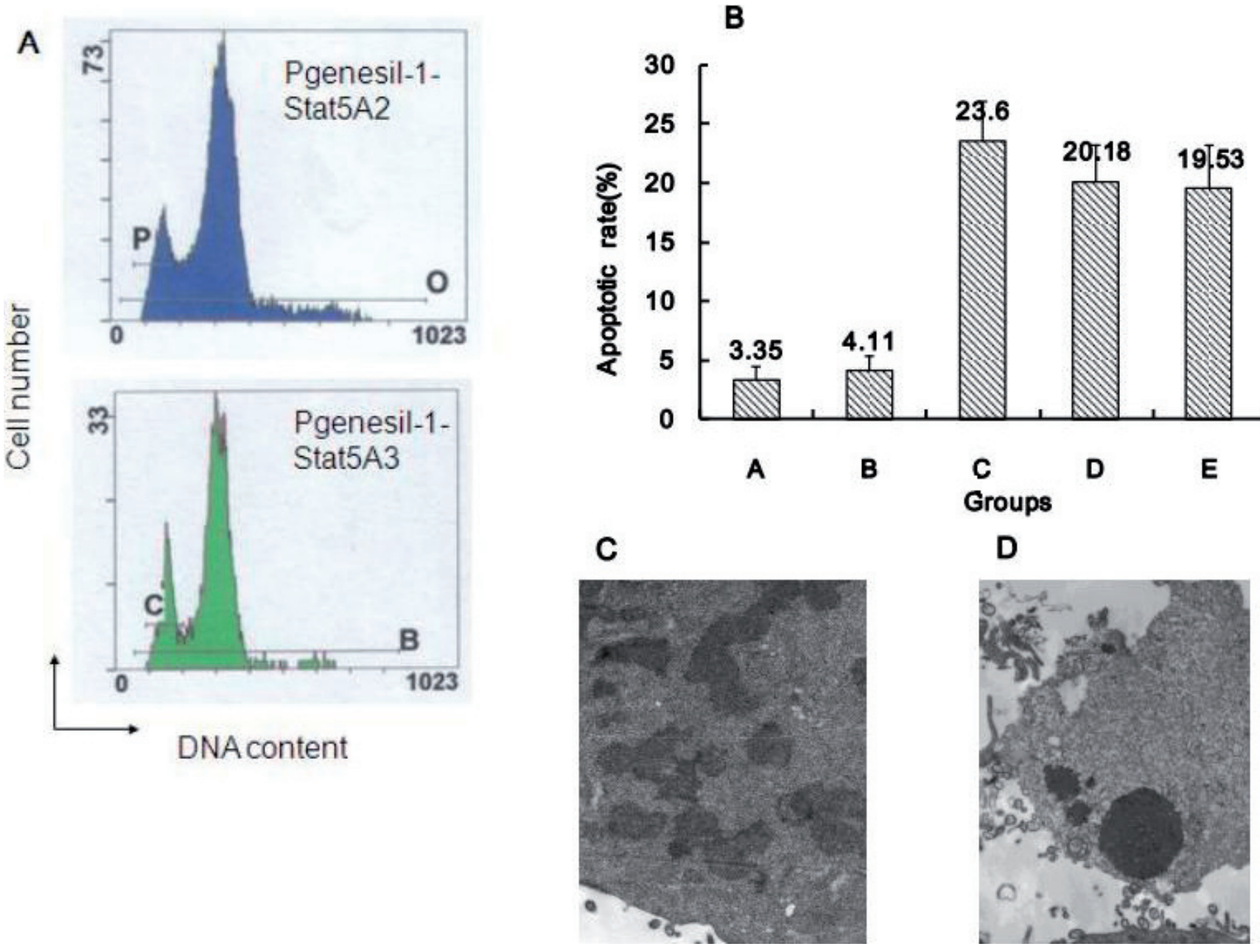

Fig. 3. Stat5 knockdown induces the apoptosis of SMMC7721 cells. A. Representative flow cytometry histograms of SMMC7721 cells treated with Pgenesil-1-Stat5A2 and Pgenesil-1-Stat5A3. B. Quantification of apoptosis rate in different groups (A: Untreated group; B: Pgenesil-1-HK group; C: Pgenesil-1-Stat5A1 group; D: Pgenesil-1-Stat5A2 group; and E: Pgenesil-1-Stat5A3 group) $(n=3)$. All data were expressed as means \pm S.D and the bar represented the mean of data obtained from three experiments. C. Transmission electron microscopy showing the ultrastructure of SMMC7721 cells transfected with Pgenesil-1-Stat5A2. D. Transmission electron microscopy showing the ultrastructure of apoptotic SMMC7721 cells transfected with Pgenesil-1-Stat5A3. The cells exhibited typical apoptotic features such as chromatin condensation, nuclear fragmentation, presence of apoptotic bodies, and cytoplasm vacuolization. Magnification: $\mathbf{x 5 0 0 0}$.

as induced by Pgenesil-1-Stat5A1 (Fig. 3). When summarizing, these results demonstrated that Stat5 knockdown promotes the apoptosis of SMMC7721 cells.

Stat5 knockdown inhibits the growth of tumor xenograft in nude mice. To investigate the in vivo role of Stat5 in hepatocellular carcinoma, we performed tumor xenograft experiments. The tumor growth curves showed that the tumor derived from SMMC7721 cells in the control groups continued to grow. In contrast, the tumor derived from SMMC7721 cells in the Pgenesil-1-Stat5A1 group grew slowly (Fig. 4A). On the day 20 after the last injection, we measured the weight and volume of tumor in the three experimental groups. The results showed that the weight and volume of tumor in NS group $\left(3.10 \pm 0.25 \mathrm{~g}\right.$ and $605 \pm 15 \mathrm{~mm}^{3}$, respectively) and Pgenesil-1-HK group ( $3.05 \pm 0.20 \mathrm{~g}$ and $595 \pm 13 \mathrm{~mm}^{3}$, respectively) were significantly higher than that in Pgenesil-1-Stat5A1 group $\left(1.32 \pm 0.19 \mathrm{~g}\right.$ and $256 \pm 10 \mathrm{~mm}^{3}$, respectively) $(p<0.01)$ (Fig. $4 \mathrm{~B})$. The inhibitory rate was $57.7 \%$.

To confirm that the inhibition of xenograft growth is due to the induction of apoptosis by Stat 5 knockdown, we examined the apoptosis of SMMC7721 cells isolated from different xenografts. Flow cytometry analysis showed that the apoptosis rate in Pgenesil-1-Stat5A1 group (21.35 $\pm 3.69 \%)$ was significantly higher than in the control NS group $(3.56 \pm 1.12 \%)$ and Pgenesil-1-HK group (3.81 $\pm 3.05 \%)(p<0.05$, Fig. 5). As expected, Western blot analysis demonstrated that Stat 5 protein expression was significantly lower in xenografts 
A

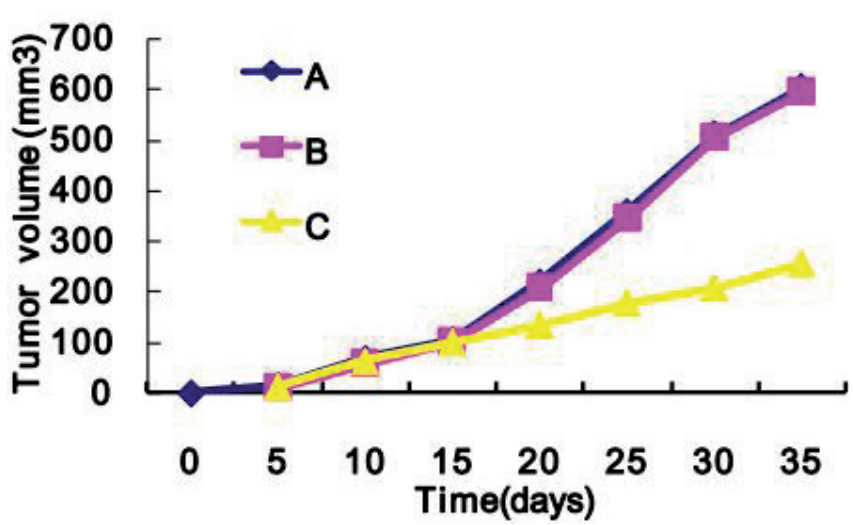

B

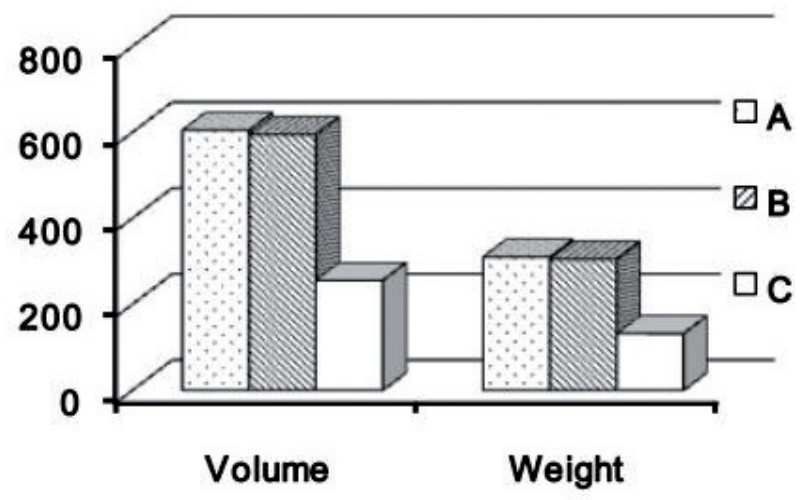

Fig. 4. Stat5 knockdown inhibits the growth of SMMC7721 xenograft in nude mice. A. Tumor growth curves of SMMC7721 xenografts in different groups (A: Untreated group; B: Pgenesil-1-HK group; C: Pgenesil-1-Stat5A1 group). Note that the tumor in the control groups A and B continued to grow while the tumor in group C grew slowly. B. The volume and weight of SMMC7721 xenografts in different groups (A: Untreated group; B: Pgenesil1-HK group; C: Pgenesil-1-Stat5A1 group) on the thirty-fifth day.

The weight and volume of tumor in group C (weight: $1.32 \pm 0.19 \mathrm{~g}$, volume: $256 \pm 10 \mathrm{~mm}^{3}$ ) was significantly less than group A (weight: $3.10 \pm 0.25 \mathrm{~g}$, volume: $605 \pm 15 \mathrm{~mm}^{3}$ ) and group B (weight: $3.05 \pm 0.20 \mathrm{~g}$, volume: $\left.595 \pm 13 \mathrm{~mm}^{3}\right)(p<0.01)$. The inhibitory rate of tumor growth was $57.7 \%$.

derived from Pgenesil-1-Stat5A1 group than in xenografts derived from control NS group and Pgenesil-1-HK group (Fig. 6). Taken together, these in vivo data complement the in vitro data shown above and support that Stat5 knockdown induces the apoptosis of SMMC7721 cells to inhibit the tumorigenesis.
A
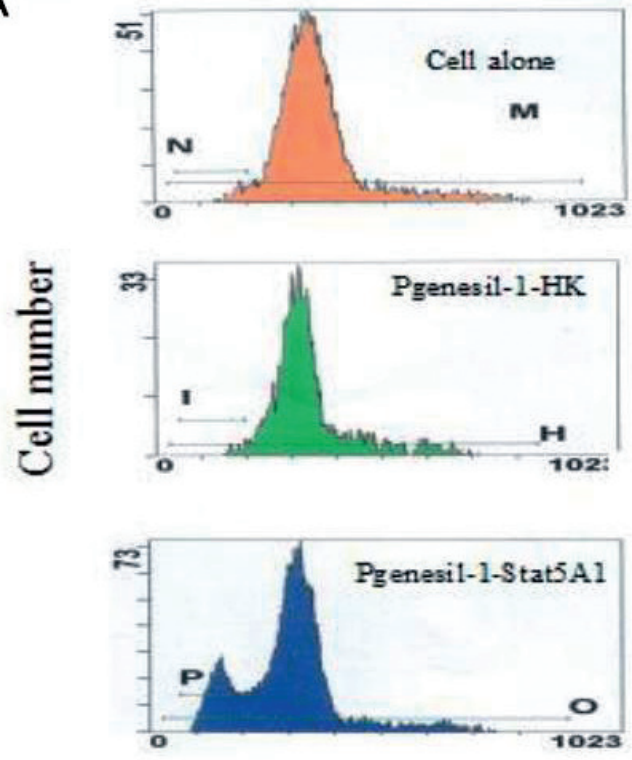

DNA Content
B

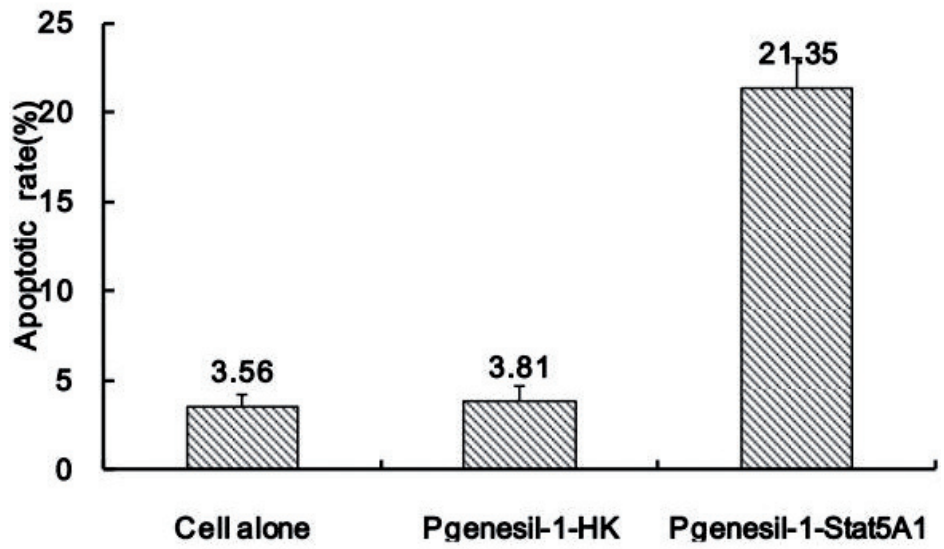

Fig. 5. Stat5 knockdown induces the apoptosis of SMMC7721 xenografts. A. Representative flow cytometry histograms of different groups. Typical sub-diploid population or sub-G1 peak was observed in SMMC7721 cells isolated from xenograft derived from SMMC7721 cells treated with Pgenesil1-Stat5A1. B. Quantification of apoptosis rate in different groups based on histograms shown in $A(n=5)$. All data were expressed as means \pm S.D and the bar represented the mean of data obtained from five experiments. ${ }^{*} p<0.05$ compared to the cells alone. 
A

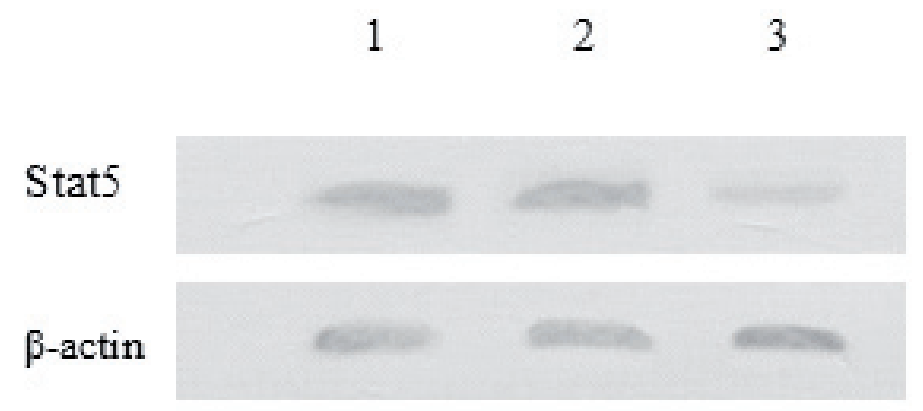

B

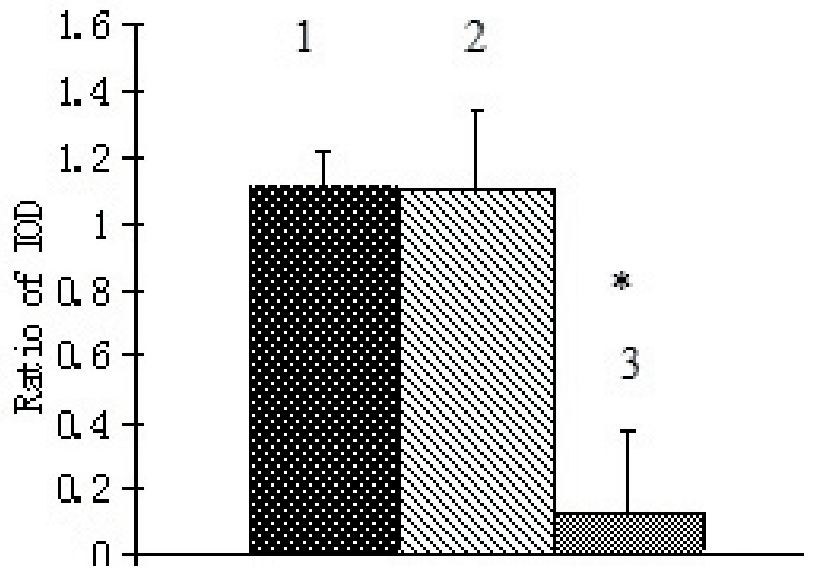

Fig. 6. shRNA mediated silencing of Stat 5 expression in SMMC7721 xenograft in nude mice. A. Representative Western blots showing the relative Stat5 protein level in different groups of xenografts. 1: Untreated cells; 2: Pgenesil-1- HK; 3: Pgenesil-1-Stat5A1. B. Quantification of Stat5 protein level (normalized to the $\beta$-actin protein level) as shown in $A(n=3)$. All data were expressed as means $\pm S$.D and the bar represented the mean of data obtained from three experiments. ${ }^{\star} p<0.05$ compared to group 1 and 2 .

\section{Discussion}

Previous studies have shown the constitutive activation of Stat5 in a wide variety of human cancer cell lines and primary tumors, including both blood malignancies such as leukemia, lymphomas, and multiple myeloma, and solid tissues tumor such as head and neck, breast, and prostate cancers [9-11]. However, up to date, no published studies have investigated the expression and role of Stat 5 in human hepatocellular carcinoma. In the present study, we reported for the first time that Stat5 was expressed at high level in SMMC7721 human hepatocellular carcinoma cell line. Thus we speculate that Stat5 may play oncogenic role in human hepatocellular carcinoma.

To elucidate the role of Stat5 in human hepatocellular carcinoma, we employed the loss of function approach to knockdown Stat5 in SMMC7721 cells. We designed and synthesized three shRNA sequences targeting the shared region of both Stat5a and Stat $5 b$ genes. Further analysis showed that Pgenesil-1-Stat5A1 shRNA exhibited the strongest effect in silencing Stat 5 expression in these cells. Thus this vector was selected to deplete Stat5 in SMMC7721 cells for the analysis of the in vitro and in vivo significance of Stat 5 knockdown. Our results demonstrate that Stat5 shRNA induced the apoptosis and inhibited the growth of SMCC7721 cells and the derived xenograft in vitro and in vivo. These results are consistent with a recent study reporting that siRNA-mediated Stat3 knockdown inhibited breast tumor growth and metastasis in mice [12].

Stat 5 is represented by two highly homologous genes encoding Stat $5 \mathrm{a}$ and Stat $5 \mathrm{~b}$, which are activated in response to a variety of cytokines and growth factors, as well as by oncogenic tyrosine kinases such as Bcr-Abl. Gene-disruption experiments have revealed that Stat5a and Stat $5 b$ are not functionally redundant [13]. Further studies are necessary to investigate whether the Stat5a and Stat5b two isoforms have similar or different function in regulating hepatocelluar carcinoma and apoptosis.

Stat5 is known to regulate the expression of a diversity of apoptosis related proteins such as XIAP and Bcl-xL, and activated Stat5 conferred resistance to apoptosis in Bcr-Abl-positive CML cells partially by upregulating $\mathrm{Bcl}-\mathrm{xL}[14,15]$. Another antiapoptotic protein $\mathrm{Mcl}-1$ was shown to be regulated by Stat 5 in CML cells and Mcl-1 contributed to Stat-dependent delayed apoptosis in human neutrophils [16]. Survivin, a target gene of Stat5, was highly expressed in colorectal carcinoma and closely correlated to its clinicopathologic parameters [17]. Based on these data, we speculate that Stat5 may enhance the expression of anti-apoptosis proteins such as Bcl-xL or survivin which act as downstream effectors to promote the survival of hepatocellular carcinoma cells.

On the other hand, Stat5b activation has been shown to promote hepatocellular carcinoma aggressiveness through the induction of epithelial-mesenchymal transition, an important aspect of tumor metastasis [18]. However, it remains unclear whether the activation of Stat 5 is a primary event in the development of liver cancer or the result of malignant transformation. Interestingly, recent data suggest that in the liver, growth hormone $(\mathrm{GH})$ binds its cognate receptor (GHR) to active JAK2/STAT5 signaling [19]. Further studies are necessary to characterize the molecular mechanisms underlying 
constitutive activation of STAT5 in human hepatocellular carcinoma cells.

In summary, our findings provide the first evidence for the oncogenic role of Stat5 in hepatocellular carcinoma and suggest that Stat 5 shRNA holds promise as a novel gene therapy vector for hepatocellular carcinoma.

Acknowledgements: We thank Dongjiang Song and Zhiping Chen for critical reading of the manuscript.

\section{References}

[1] BROMBERG J, DARNELL JE JR. The role of STATs in transcriptional control and their impact on cellular function. Oncogene 2000; 19: 2468-2473. http://dx.doi.org/10.1038/ si.onc. 1203476

[2] BUNTING KD. STAT5 signaling in normal and pathologic hematopoiesis. Front Biosci 2007; 12: 2807-2820. http://dx.doi. org/10.2741/2274

[3] DiAZ T, NAVARRO A, FERRER G, GEL B, GAYA A, et al. Lestaurtinib inhibition of the Jak/STAT signaling pathway in hodgkin lymphoma inhibits proliferation and induces apoptosis. PLoS One 2011;6:e18856. http://dx.doi. org/10.1371/journal.pone.0018856

[4] THOMAS C, ZOUBEIDI A, KURUMA H, FAZLI L, LAMOUREUX F, et al. Transcription factor Stat5 knockdown enhances androgen receptor degradation and delays castration-resistant prostate cancer progression in vivo. Mol Cancer Ther. 2011; 10: 347-359. http://dx.doi.org/10.1158/1535-7163. MCT-10-0850

[5] YU H, JOVE R. The STATs of cancer-new molecular targets come of age. Nat. Rev. Cancer 2004; 4: 97-105. http://dx.doi. org/10.1038/nrc1275

[6] LIN JX, LEONARD WJ. The role of Stat5a and Stat5b in signaling by IL-2 family cytokines. Oncogene 2000; 19: 2566-2576. http://dx.doi.org/10.1038/sj.onc.1203523

[7] MOSMANN T. Rapid colorimetric assay for cellular growth and survival: application to proliferation and cytotoxicity assays. J Immunol Methods 1983; 65: 55-63. http://dx.doi. org/10.1016/0022-1759(83)90303-4

[8] HUYNH H, LEE JW, CHOW PK, NGO VC, LEW GB, LAM IW et al. Sorafenib induces growth suppression in mouse models of gastrointestinal stromal tumor. Mol Cancer Ther. 2009; 8: 152-159. http://dx.doi.org/10.1158/1535-7163.MCT$\underline{08-0553}$
[9] MISHRA R, DAS BR. Activation of STAT 5-cyclin D1 pathway in chewing tobacco mediated oral squamous cell carcinoma. Mol Biol Rep. 2005; 32: 159-166. http://dx.doi.org/10.1007/ $\underline{\text { s11033-005-0754-9 }}$

[10] SONG JI, GRANDIS JR. STAT signaling in head and neck cancer. Oncogene 2000; 19: 2489-2495. http://dx.doi. org/10.1038/sj.onc. 1203483

[11] COFFER PJ, KOENDERMAN L, DE GROOT RP. The role of STATs in myeloid differentiation and leukemia. Oncogene 2000; 19: 2511-2522.

[12] DAI L, CHENG L, ZHANG X, JIANG Q, ZHANG S, et al. Plasmid-based STAT3-siRNA efficiently inhibits breast tumor growth and metastasis in mice. Neoplasma 2011; 58: 538-547. http://dx.doi.org/10.4149/neo $2011 \quad 06 \quad 538$

[13] BUETTNER R, MORA L B, JOVE R. Activated STAT Signaling in Human Tumors Provides Novel Molecular Targets for Therapeutic Intervention. Clin. Cancer Res. 2002; 8: 945-954.

[14] SOCOLOVSKY M, FALLON AE, WANG S, BRUGNARA C, LODISH HF. Fetal anemia and apoptosis of red cell progenitors in Stat $5 \mathrm{a}-/-5 \mathrm{~b}-/-$ mice: a direct role for Stat 5 in Bcl-X(L) induction. Cell 1999; 98: 181-191. http://dx.doi.org/10.1016/ S0092-8674(00)81013-2

[15] GESBERT F, GRIFFIN JD. Bcr/Abl activates transcription of the Bcl-X gene through STAT5. Blood 2000; 96: 22692276.

[16] EPLING-BURNETTE PK, ZHONG B, BAI F, JIANG K, BAILEY RD, GARCIA R, JOVE R, DJEU J Y, LOUGHRAN TP, WEI S. Cooperative regulation of Mcl-1 by Janus kinase/Stat and phosphatidylinositol 3-kinase contribute to granulocytemacrophage colony-stimulating factor-delayed apoptosis in human neutrophils. J. Immunol. 2001; 166: 7486-7495.

[17] LIANG QL, WANG BR, LI GH. DcR3 and survivin are highly expressed in colorectal carcinoma and closely correlated to its clinicopathologic parameters. J Zhejiang Univ Sci B. 2009;10:675-682. http://dx.doi.org/10.1631/jzus.B0920077

[18] LEE TK, MAN K, POON RT, LO CM, YUEN AP et al. Signal transducers and activators of transcription $5 \mathrm{~b}$ activation enhances hepatocellular carcinoma aggressiveness through induction of epithelial-mesenchymal transition. Cancer Res. 2006; 66: 9948-9956. http://dx.doi.org/10.1158/0008-5472. CAN-06-1092

[19] BAIK M, YU JH, HENNIGHAUSEN L. Growth hormoneSTAT5 regulation of growth, hepatocellular carcinoma, and liver metabolism. Ann N Y Acad Sci. 2011; 1229: 29-37. http://dx.doi.org/10.1111/j.1749-6632.2011.06100.x 